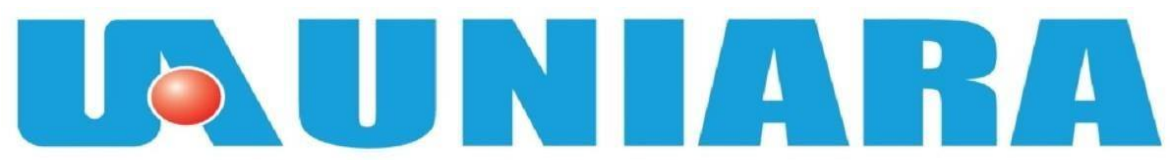

UNIVERSIDADE DE ARARAQUARA

UNIVERSIDADE DE ARARAQUARA-UNIARA

GRACIÉLE BARÃO MERENCIANO

https://doi.org/10.47820/recima21.v2i11.985

\title{
ESTUDO DE CASO DO SISTEMA DE DRENAGEM URBANA E SUA RELAÇÃO COM O MEIO AMBIENTE EM UM BAIRRO NO MUNICÍPIO DE ARARAQUARA-
} SP

Trabalho apresentado no curso de graduação da Universidade de Araraquara.

Orientador: Eng. Civil Alexandre Coan Pierri 


\section{INTRODUÇÃO}

A drenagem pluvial urbana trata-se da ação de gerenciar e destinar o transporte, retenção, tratamento e disposição final das águas das chuvas. Auxilia no aspecto social, legal, institucional, tecnológico e ambiental de toda urbanização, com plano diretor da cidade estabelecido é correto afirmar que a base da cidade e seus interesses estão delineados.

A Constituição Federal de 1988, pela Lei № 11.445 assegurado que o sistema de drenagem pluvial, "No Brasil, o saneamento básico é um direito assegurado pela Constituição Federal de 1988 e pela Lei no. 11.445/2007 como o conjunto dos serviços, infraestrutura e instalações operacionais de abastecimento de água, esgotamento sanitário, limpeza urbana, drenagem urbana, manejos de resíduos sólidos e de águas pluviais."

Nota-se que devido ao processo citado acima e a forma acelerada de ocupação da cidade, preocupa na questão de drenar toda água, não absorvida pela permeabilidade do solo ou captada pelo sistema de drenagem. Dentro do estudo da microdrenagem do bairro, foi definida pela bacia de acordo principalmente pelo traçado das ruas.

Nos municípios a decisão de todo andamento da cidade cabe ao Prefeito, portanto a verba destinada a drenagem pluvial, que sofre pelo giro de gestores nos setores, o que impede um padrão de sistema, o mapeamento adequado das galerias e a implantação por partes das galerias pluviais.

Entretanto, essas tomadas de decisões não impendem a implantação da galeria no bairro estudado de forma adequada, pois é realizado um estudo do local e separado por bacias e sub-bacias para suportar a precipitação da área. Por isso, se tratando de drenar toda essa água, a estrutura vai desde sarjetas até seu destino final, lagoas, córregos ou rios.

De acordo com o relatório da OMS (2014), os benefícios do investimento em água e saneamento estão ligados a diminuição da poluição nos recursos hídricos e da terra. São destacados os ecossistemas aquáticos, a valorização da terra, a reutilização de nutrientes como geração de biogás e a oportunidade de expandir o turismo, devido a um ambiente mais limpo, menos insalubre e com mais atrativos.

Neste contexto, o município deve justamente incentivar o descarte correto do lixo urbano, a separação de cada tipo de resíduo e oferecer locais em pontos estratégicos da cidade para esse descarte. Nesta visão geral e em seu significado, o meio ambiente não é só parte de uma boa drenagem, e sim, essencial para drenagem correta e para a população em todos os sentidos.

Este estudo visa instrumentalizar decisões quanto às técnicas adequadas para implantação de galerias pluviais utilizando o estudo de um caso real, a relação com o meio ambiente e alternativas técnicas atuais para auxílio de menos custos e mais eficiência nos projetos.

De acordo com Tucci (1993), o sistema de drenagem urbana sustentável divide-se em dois métodos: estruturais e não estruturais. Os métodos estruturais têm o embasamento na construção que reduza os impactos causados pelas enchentes, e subdividem-se em extensivas ou intensivas.

As extensivas operam na bacia e modificam as relações entre precipitação e vazão, com redução e retardamento nos picos de enchentes e do controle de erosão na bacia agindo, principalmente no controle de inundações frequente.

As intensivas operam sobre rio e podem ser representadas de quatro tipos: medidas que aceleram o escoamento; medidas que amortecem e retardam o escoamento; medidas de desvio do escoamento; e medidas que englobam a introdução de ações individuais, visando tornar as edificações à prova de enchentes.

A falta de maior divulgação do assunto, por meio de publicações, estudos e teses, retarda a chegada do conhecimento necessário para um projeto de drenagem pluvial adequado para cada região, com maior qualidade e evitando futuros retrabalhos. As consequências da implantação incorreta ou com estimativas longe da realidade, são sempre as mesmas em todo lugar, o retrabalho de um serviço finalizado, prejuízos e custos elevados de mão de obra e material a cada mudança de estação.

A análise que está sendo feito sobre o bairro Cidade Jardim, este trabalho acompanha o processo desde o início do projeto, seus problemas, sua implantação, até o fim deste curso. Com análise de documentos, pesquisas de campo e resultados, serão comparadas com uma alternativa mais sustentável, a fim de melhorar o processo atual e contribuir para projetos futuros. 


\section{DESENVOLVIMENTO}

\subsection{CIDADEJARDIM}

O projeto está localizado na cidade de Araraquara, no bairro Cidade Jardim região norte da cidade, os primeiros dados mostram uma área aproximada de $693.000 \mathrm{~m}^{2}$, contando com 700 lotes. Todos os documentos, dados e figuras disposto ao longo deste trabalho foram documento cedidos pela Prefeitura do Município de Araraquara.

A drenagem não foi executada no período em que foram feitos os primeiros estudos em 2011, neste período ocorreu um estudo mais aprofundado do bairro liderado pelo engenheiro civil Paulo Vaz Filho e dados coletados pela empresa Ville Projetos de Engenharia S/S Ltda. Nesta análise técnica, foram obtidos os dados do dimensionamento da bacia, implantação da galeria pluvial, topografia do bairro, verificação de vazão da sarjeta, tabela de projeção da vazão da galeria pluvial e uma planilha de orçamento básico.

Os últimos estudos iniciados em 2020 foram mais sucintos e o início de implantação está sendo realizados pela Secretaria de Obras e Serviços Públicos da Prefeitura Municipal de Araraquara com recurso próprio. Nesta primeira fase, o orçamento foi aprovado pela licitação e a verba oriundo do Estado, ou seja, valor disposto.

É necessário ressaltar que a implantação da galeria do bairro, foi divido em 4 fazes devido seu valor ultrapassar os $\mathrm{R} \$ 7.000 .000,00$, e não seria possível arrecadar tal valor no momento de recurso próprio.

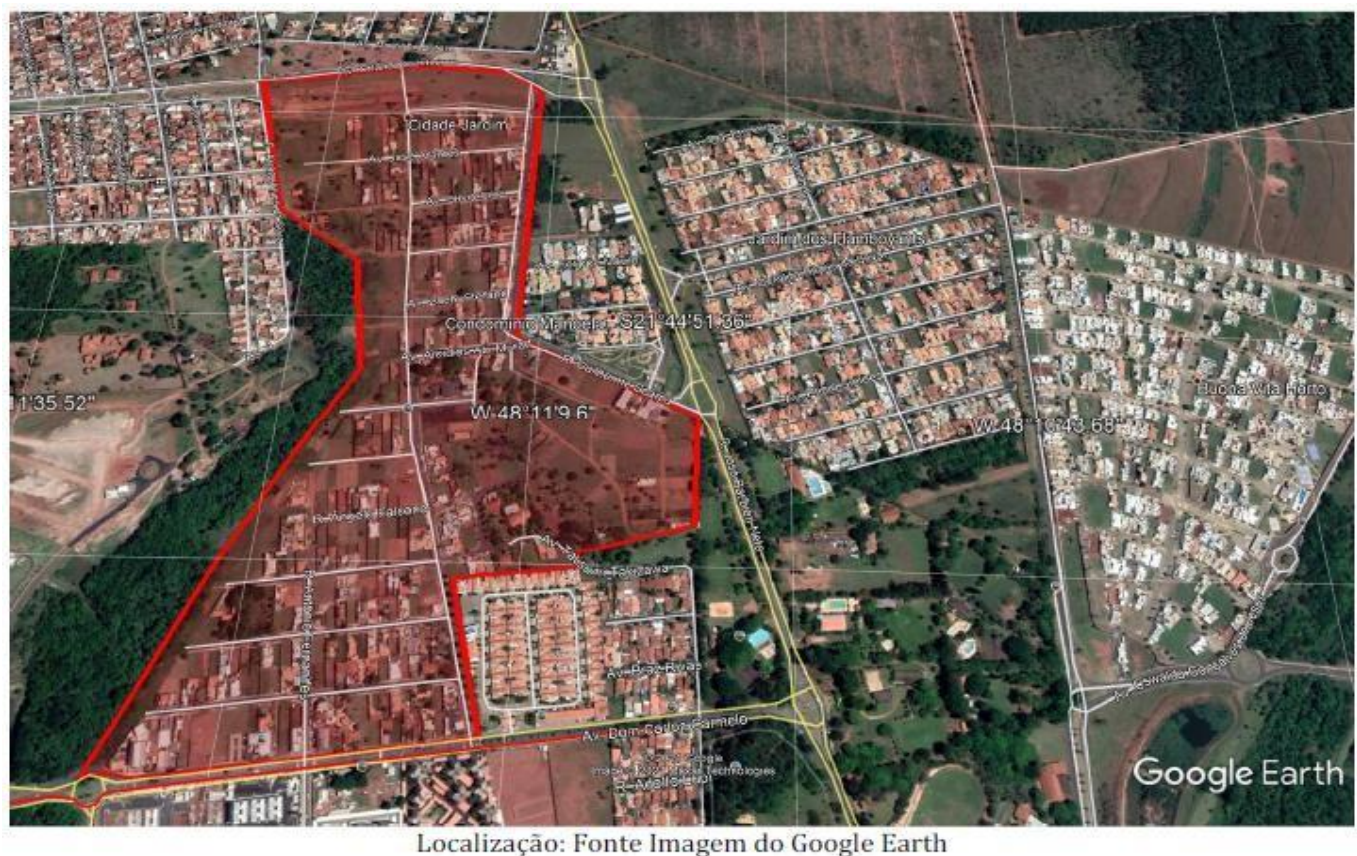

\subsection{TOPOGRAFIA}

O método mais utilizado para é o planialtimétrico, capaz de coleta informações dos diferentes níveis do terreno, fazendo projeções horizontais e medir as diferenças de altura do relevo.

O levantamento foi feito com um método mais novo, que futuramente se tornara o mais usual, que é a geotecnologia, ou seja, a área de estudo ou investigação, gera resultados a partir da localização geográfica, capaz de medir ângulos e distância através de um taqueômetro tecnicamente conhecido como estação total ou fotos aéreas do relevo, sendo esta última utilizada no bairro estudado.

A topografia da região baseado nos pontos tirados com a estação total topográfica modelo Kolida CTS, os pontos atingidos, são de acordo com a referência e delimitação escolhido para projeto.

No bairro Cidade Jardim foi utilizado o aparelho com georreferenciamento fotográfico, após colher todos os pontos, os dados são inseridos no programa datageosis, um software de georreferenciado, isso significa um conjunto de topografia e suas coordenadas geográficas. Então os pontos de cotas de níveis, estão prontos para ser inserido no software de desenho, o AutoCAD, para obtermos um mapeamento da região mais preciso e mais próximo da realidade. 


\subsection{Baciase Sub-bacias}

Segundo a revista Rega, $O$ escoamento natural de uma bacia hidrográfica é significativamente alterado pelo processo de urbanização, que consequentemente ocorre um aumento do volume de águas pluviais escoadas superficialmente, o acréscimo das vazões dos corpos d'água, geração de sedimento, a degradação da qualidade da água, entre outros.

O Córrego do Cupim pertence à bacia hidrográfica Tietê-Jacaré e Sub-bacia Ribeirão das Cruzes, a área da microbacia possui aproximadamente $4,35 \mathrm{~km}^{2}$. É evidente que o córrego em questão, é muito importante para o ambiente que manterá vida no planeta, fazendo parte diretamente na qualidade e quantidade da água, servindo para diferentes usos do ser humano e o abastecimento das residências.

A Microbacia do Córrego do Cupim não faz parte do sistema de captação de água superficial, quer dizer que não é considerado um manancial. Seu papel se estende principalmente nos âmbitos de conservação da biodiversidade local (fauna e flora) em zona urbana, melhoria na qualidade do ar, sensibilização ambiental pelo convívio diário com a natureza e educação ambiental através experiências promovidas com tal finalidade.

No Córrego do Cupim, sua nascente está localizada entre a Rua Carmino Brambilla (Cidade Jardim) e Rua Álvaro Alves da Silva (Maria Luiza IV). Seu trajeto, por consequência, inicia no bairro Cidade Jardim e termina entre os bairros Residenciais Cambuy e Jardim Residencial Paraíso, próximo ao início da Rua Julieta Cruscade Jesus com extensão superior a 2 km.

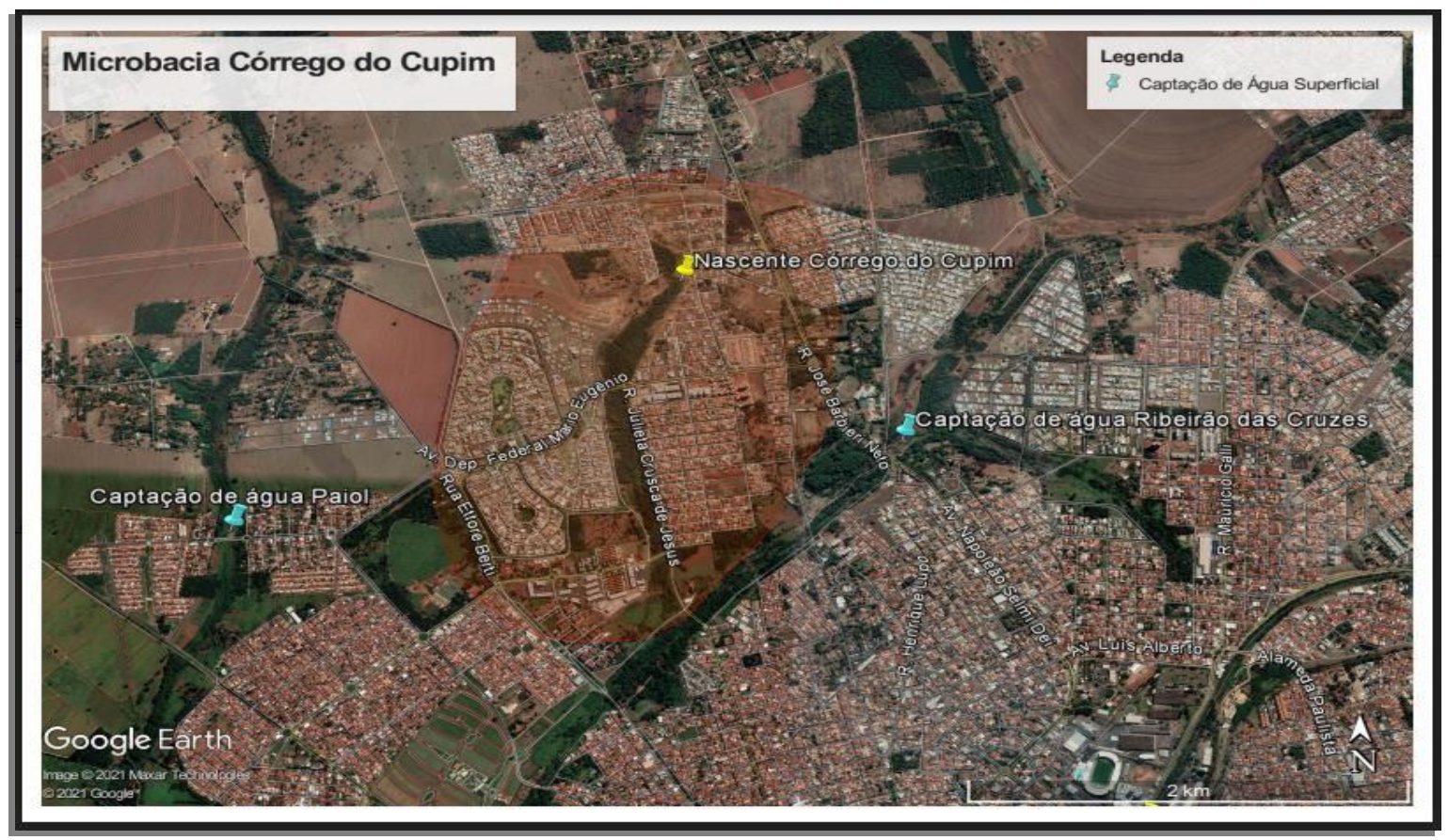

A bacia estuda é denominada como bacia de pequeno porte, sendo possível assim a utilização do método Racional, foram divididas em quatro áreas:

Bacia I: $214.848,47 \mathrm{~m}^{2}$;

SUB-BACIAS

1-1: $13.700,35 \mathrm{~m}^{2} / 1: 2: 15.160,69 \mathrm{~m}^{2} / 1-3: 3.637,40 \mathrm{~m}^{2} / 1-4: 21.824,06 \mathrm{~m}^{2}$

1-5: $18.112,43 m^{2}$ / 1-6: $6.153,90 m^{2}$ / 1-7: $19.055,95 m^{2} / 1-8: 14.468,44 m^{2}$

1-9: $18.898,22 \mathrm{~m}^{2} / 1-10: 6.984,22 \mathrm{~m}^{2} / 1-11: 3.493,37 \mathrm{~m}^{2} / 1-11 \mathrm{~A}: 1.796,26 \mathrm{~m}^{2}$

1-12: $17.643,03 \mathrm{~m}^{2} / 1-13: 4.895,00 \mathrm{~m}^{2} / 1-14: 3.800,00 \mathrm{~m}^{2} /$

1-14A: $2.597,12 \mathrm{~m}^{2} / 1-15: 18768.27 \mathrm{~m}^{2} / 1-16: 1824.83 \mathrm{~m}^{2}$

1-17: $15648.96 \mathrm{~m}^{2} / 1-18: 6.378,65 \mathrm{~m}^{2}$

Bacia II: 81.429,85 m²; 
SUB-BACIAS

2-1: $20.193,53 m^{2}$ / 2-2: $3.188,59 m^{2}$ / 2-3: $16.678,20 m^{2}$ / 2-4: $19.596,15 m^{2}$ 2-5: $12.788,26 \mathrm{~m}^{2}$ / 2-6: $5.098,65 \mathrm{~m}^{2} / 2-7: 3.951,37 \mathrm{~m}^{2}$

Bacia III: 114.449,66 m²;

SUB-BACIAS

3-1: $3.849,76 \mathrm{~m}^{2}$ / 3-2: $30.686,20 \mathrm{~m}^{2}$ / 3-3: $8.375,90 \mathrm{~m}^{2}$ / 3-4: $3.669,88 \mathrm{~m}^{2}$

3-5: $28.080,48 \mathrm{~m}^{2}$ / 3-6: $2.138,35 \mathrm{~m}^{2}$ / 3-7: $33.855,06 \mathrm{~m}^{2} / 3-8: 3.794,31 \mathrm{~m}^{2}$

Bacia VI: 48.504,79 m²

Bacias:

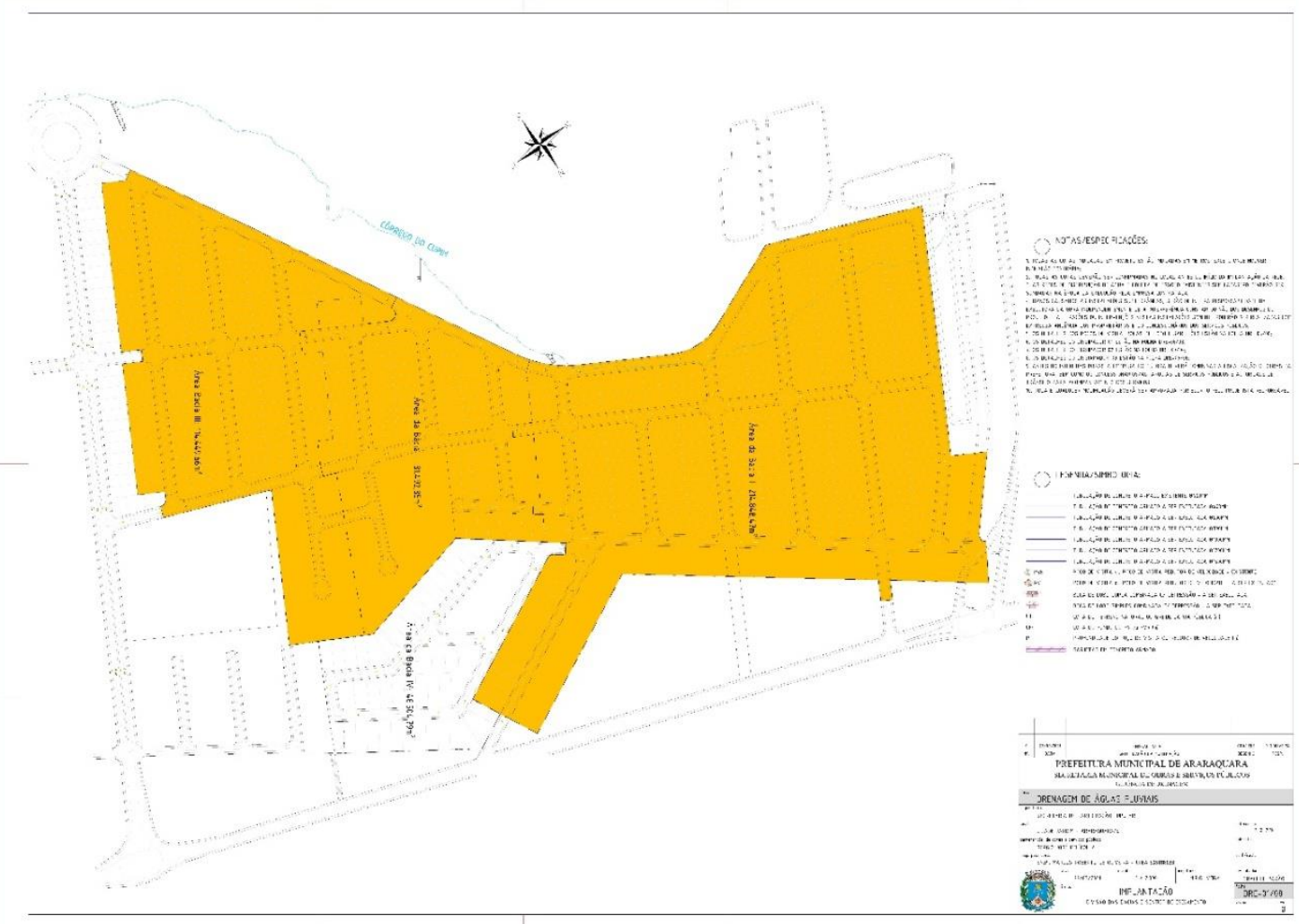

Sub-Bacias 


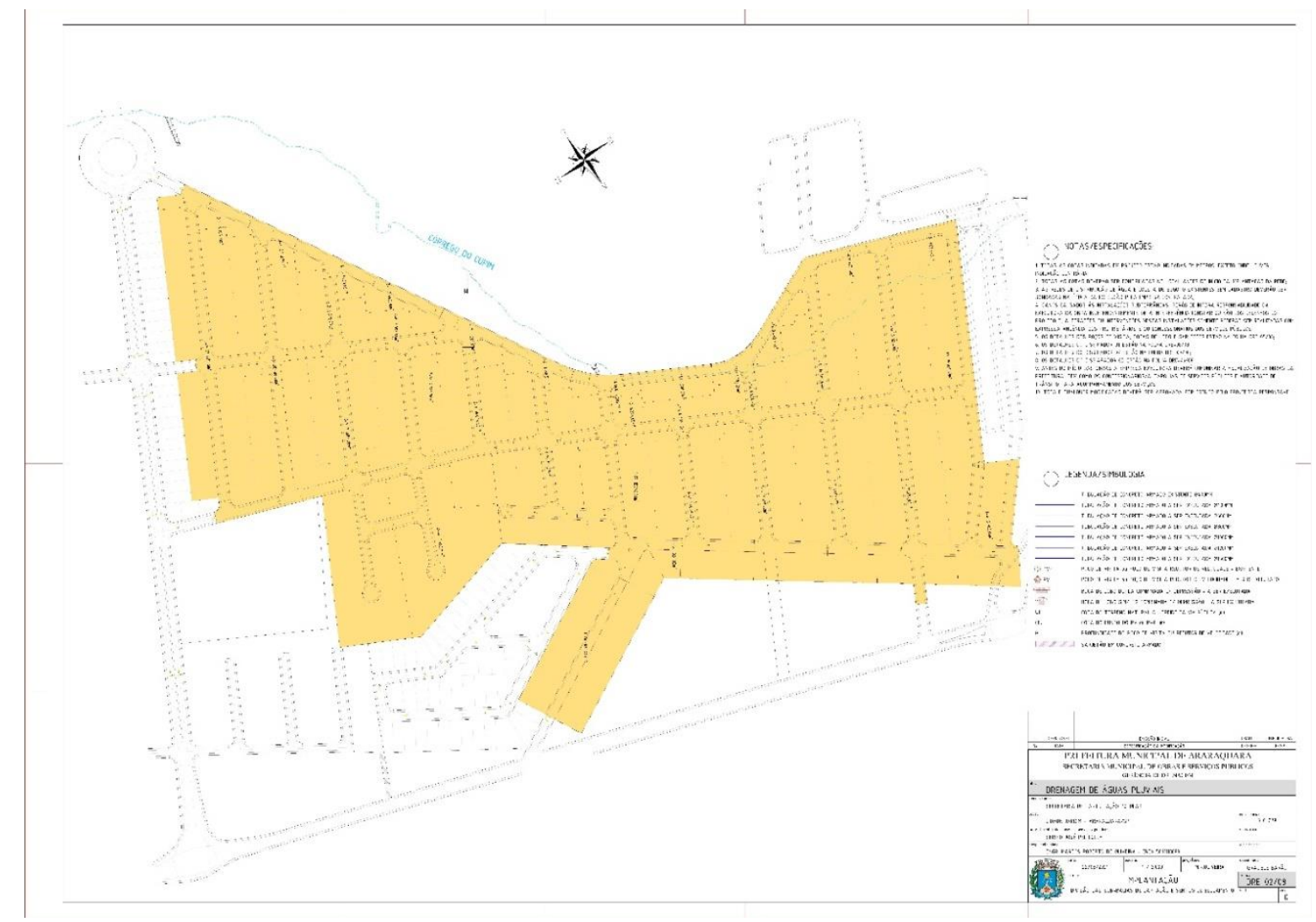

\subsection{IMPLANTAÇÃO}

De acordo com Tucci (2004) a ocupação do solo determina o cenário do escoamento natural que não é dividida corretamente, sendo $n$ zona urbana definida pelo traçado das ruas.

Para o cálculo e dimensionamento das galerias foi utilizado o método racional, baseada na equação de Manning que fornece o valor da velocidade, vazão para certo diâmetro adotado e a equação In In de Araraquara para intensidade da chuva na região.

Considerou - se regime permanente e uniforme, a tubulação de concreto armado, de seção circular, operando em condição de seção plena, contudo, como conduto livre. O diâmetro mínimo da tubulação de $600 \mathrm{~mm}$, com velocidade máxima de $5,00 \mathrm{~m} / \mathrm{s}$ e velocidade mínima de $0,75 \mathrm{~m} / \mathrm{s}$.

As bocas de lobo apresentadas em detalhe, indicadas em planta, que apresentam capacidade de engolimento de $50 \mathrm{~L} / \mathrm{s}$, os ramais de ligação em tubos de concreto de diâmetro de $400 \mathrm{~mm}$ para todas as ligações de bocas de lobo, com declividade mínima de 1,5\%.

\subsection{MEMORIAL DE CALCULO}

O tempo de retorno $(\mathrm{T})$ - é quando se determina um intervalo de tempo para um evento hidrológico é igualado ou superado ao menos uma vez. Adotado para o cálculo do bairro $=10$ anos.

O tempo de concentração (tc) - deve ser usado as fórmulas de Kirpich para o tempo de concentração. Onde tc = é tempo de concentração, dado em min; $L=$ é o comprimento do talvegue, dado em $\mathrm{km} ; \mathrm{S}$ = é a declividade do talvegue, dado em $\mathrm{m} / \mathrm{m}$ e H = é a diferença entre as cotas da seção de saída e o ponto mais a montante da bacia, dado em $\mathrm{m}$.

$$
t_{c}=3,989 \times \boldsymbol{L}^{0,77} \times \boldsymbol{S}^{-0,385}
$$

A duração da chuva de projeto (D): deve se igualado ao tempo de concentração (tc).
A previsão máxima de chuvas em Araraquara 
Tabela 3.5 - Araraquara: Previsão de máximas intensidades de chuvas, em mm/h

\begin{tabular}{|c|c|c|c|c|c|c|c|c|c|}
\hline Duração t & \multicolumn{10}{|c|}{ Período de retorno T (anos) } \\
\cline { 2 - 11 } (minutos) & $\mathbf{2}$ & $\mathbf{5}$ & $\mathbf{1 0}$ & $\mathbf{1 5}$ & $\mathbf{2 0}$ & $\mathbf{2 5}$ & $\mathbf{5 0}$ & $\mathbf{1 0 0}$ & $\mathbf{2 0 0}$ \\
\hline \hline $\mathbf{1 0}$ & 115,8 & $138, \mathbf{2}$ & 153,1 & 161,5 & 167,4 & 171,9 & 185,9 & 199,8 & 213,6 \\
\hline $\mathbf{2 0}$ & 86,2 & 104,9 & $\mathbf{1 1 7 , 2}$ & 124,2 & 129,1 & 132,9 & 144,5 & 156,0 & 167,5 \\
\hline $\mathbf{3 0}$ & 69,1 & 85,4 & 96,2 & 102,2 & 106,5 & 109,8 & 119,9 & 129,9 & 139,9 \\
\hline $\mathbf{6 0}$ & 44,1 & 56,4 & 64,5 & 69,1 & 72,3 & 74,8 & 82,5 & 90,1 & 97,6 \\
\hline $\mathbf{1 2 0}$ & 26,3 & 34,7 & 40,3 & 43,5 & 45,7 & 47,4 & 52,6 & 57,9 & 63,0 \\
\hline $\mathbf{1 8 0}$ & 19,1 & 25,0 & 28,9 & 31,1 & 32,6 & 33,8 & 37,4 & 41,0 & 44,6 \\
\hline $\mathbf{3 6 0}$ & 10,9 & 13,9 & 16,0 & 17,1 & 17,9 & 18,5 & 20,4 & 22,3 & 24,1 \\
\hline $\mathbf{7 2 0}$ & 6,1 & 7,6 & 8,7 & 9,3 & 9,7 & 10,0 & 10,9 & 11,9 & 12,9 \\
\hline $\mathbf{1 0 8 0}$ & 4,3 & 5,4 & 6,1 & 6,4 & 6,7 & 6,9 & 7,6 & 8,2 & 8,9 \\
\hline $\mathbf{1 4 4 0}$ & 3,4 & 4,2 & 4,7 & 5,0 & 5,2 & 5,3 & 5,8 & 6,3 & 6,8 \\
\hline
\end{tabular}

A Intensidade da chuva de projeto (I): é usado para determinar a quantidade de chuva pela unidade de tempo, chuva de projeto é feito com base na a equação In In de Araraquara para intensidade da chuva na região, que segue abaixo:

$$
\begin{aligned}
I_{(m m / h)}=32,4618 & \times(t+15)^{-0,868} \\
& +2,1419 \times(t+15)^{-0,582} \times\left(-0,4772-0,901 \times \ln \left(\ln \left(\frac{T_{r}}{T_{r}-1}\right)\right)\right) \times 60
\end{aligned}
$$

O calculado foi de $\mathrm{I}: 2,27 \mathrm{~mm} / \mathrm{min}$.

A vazão De Projeto $(\mathrm{Qp})$ : calculado a transformação da chuva de projeto, com fundamento no dimensionamento de galerias hidráulicas e no alcance de cotas de alerta. Assim, será utilizado o Método Racional:

$$
\mathrm{Q}=\mathrm{C} \times \mathrm{I} \times \mathrm{A}
$$

Onde, $\mathrm{Qp}=$ é a vazão de projeto, dado em $\mathrm{m}^{3} / \mathrm{s} ; \mathrm{C}=$ é o coeficiente de escoamento superficial; $\mathrm{I}=$ é a intensidade da chuva de projeto, dado em $\mathrm{mm} / \mathrm{He}$; $\mathrm{A}=$ é a área de drenagem, dado em ha; $A$ vazão para primeira fase do projeto é $7,613 \mathrm{~m}^{3} / \mathrm{s}$.

A seção molhada da rede tubular será adotada a máxima para a rede tubular correspondente à seção com altura da lâmina d'água (y) igual a $80 \%$ do diâmetro nominal da respectiva rede que será usada e $20 \%$ da mesma tubulação livre.

A capacidade das sarjetas foi determinada pela equação de Manning modificada:

Onde, Qs = é a capacidade de vazão da sarjeta, dado em $\left(\mathrm{m}^{3} / \mathrm{s}\right) ; A=$ é a área da seção transversal, dado em $\left(\mathrm{m}^{2}\right) ; \mathrm{S}=$ é a declividade longitudinal da via, dado em $\mathrm{m} / \mathrm{m}$ e $\mathrm{n}=$ é o coeficiente

de rugosidade média de Manning.

$$
\mathrm{Q}_{\mathrm{s}}=\frac{\mathrm{Ax} R h^{\frac{2}{3}} \times S^{\frac{1}{2}}}{n}
$$

Para execução do projeto, foram adotadas medidas e regras seguindo as normas e parâmetros estabelecidos pela Prefeitura Municipal, como:

Rede Tubular - A rede tubular deve ser implantada com tubos de concreto armado.

Recobrimento Mínimo - Para rede com tubos de concreto, o recobrimento mínimo sobre a geratriz externa superior é de 0,80 m. A Implantação da primeira fase de execução da galeria. 


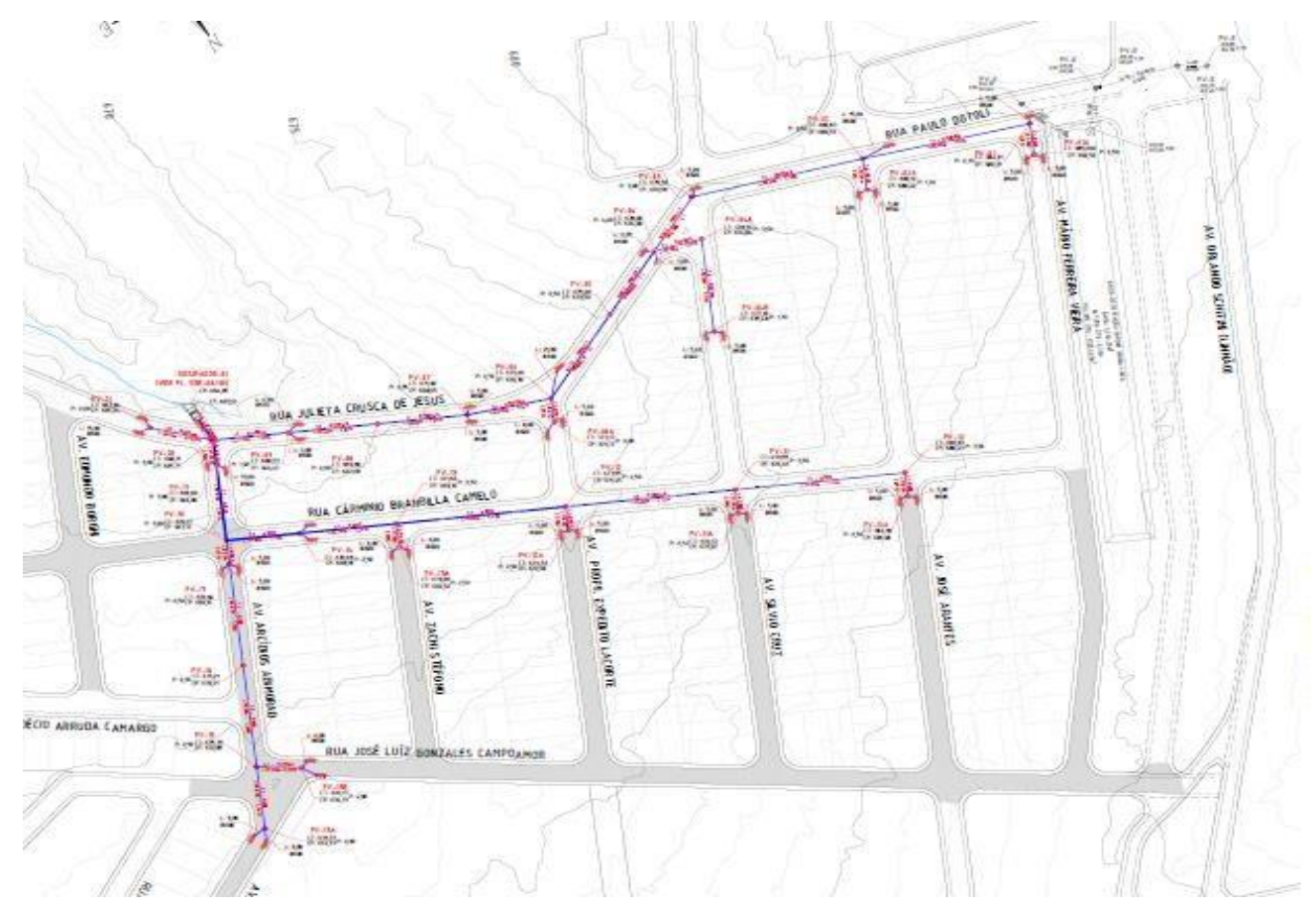

\section{INTERFERÊNCIAS}

A obra do bairro Cidade Jardim teve vários problemas desde o início da implantação da galeria, isso tudo tem a ver com a falta de infraestrutura prévia do bairro.

O primeiro problema encontrado, foi referências nas tubulações de água e esgoto do DAAE, onde tinha uma grande instalação de ramais, rede e pvs, principalmente na Av. Arcídios Abmorad, ocorrendo quebras de pvs só por proximidade ou pela escavação e queda de tubulação pela vibração próxima.

O segundo é referente a localização do dissipador por estar praticamente em cima de onde o córrego passa, muito água emergir sendo necessário colocar um tudo de dreno para conseguir concretar a base e não interferir nas propriedades do concreto.

O terceiro e até o momento maior obstáculo enfrentado foi a implantação do dissipador, onde ocorreu um remanejamento da rede do DAAE, impedindo que o nível do dissipador, baixasse mais um metro previsto em projeto.

Outro agravante neste sentido, se deve ao local determinado para o dissipador que sofreu um ajuste, ficou de frente para APP da área, ou seja, área de preservação permanente, o que caso não tivesse outra solução, poderia ocasionar uma erosão no solo, pelo contato dessa água vinda do dissipador.

Assim sua implantação foi ajustada, com reforço na parede de impacto, onde a água que chega da tubulação e bate, os dentes do dissipador ficaram maiores e após a concretagem do mesmo, será feito um muro de gabião, auxiliando na prevenção de uma possível erosão e ajudando no curso da água para o córrego. 


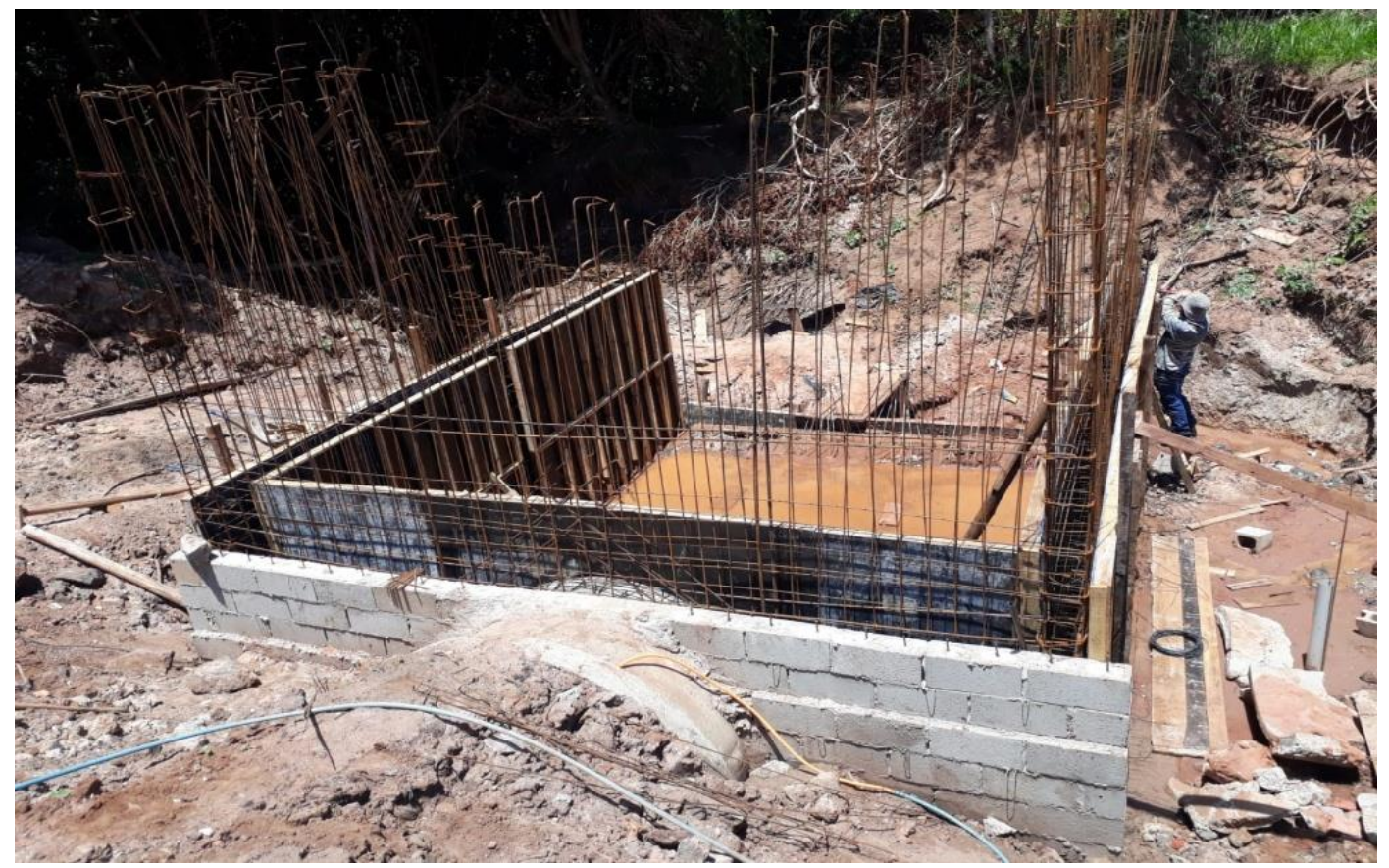

\section{RECURSOS SUSTENTÁVEIS}

A drenagem sustentável visa principalmente ter soluções naturais para a captação da água de chuva, é possível dispor de vários recursos, como exemplo, as trincheiras de infiltração, jardins de chuva, pavimentos permeáveis, reservatórios de detenção entre tantos outros.

A escolha do sistema correto depende da característica de cada projeto. O trecho de maior extensão da galeria será implantado com o sistema convencional e a água pluvial é direcionada até o córrego.

De acordo com a revista Vitrus Vius de 2020, com uma mudança de padrão, ou seja, maior incentivo as práticas sustentáveis em drenagem, tendo em contrapartida, grandes gastos com obras milionárias de macrodrenagem. A população tem a capacidade e sente-se preparado para transformar a paisagem urbana positivamente.

As designações para as técnicas sustentáveis na drenagem urbana, que surgiram e são amplamente utilizadas em países desenvolvidos, como o BMP-Best Management Practices; o LIDLow Impact Development; o SUDS-Sustainable Urban Drainage systems; o WSUD-Water Sensitive Urban Design; e o GI-Green Infrastructure.

As técnicas citadas são basicamente a junção da drenagem convencional com o meio ambiente, sendo um critério a preservação do meio e reflorestamento, agredindo o mínimo possível o meio ambiente ou até mesmo se executado conforme a proposta, somente enriquecendo o meio.

\subsection{TRINCHEIRAS DE INFILTRAÇÃO}

As são projetadas ao longo de superfícies impermeáveis destinadas a amortecer os volumes superficiais. Trata-se de uma técnica linear, na qual a dimensão de comprimento é superior às de largura e profundidade. Para implantação de sistema deve haver um estudo prévio de todos os aspectos do terreno, além da declividade do mesmo, não devendo passar de $5 \%$.

Sendo assim, um estudo realizado po Duchene, McBean e Thomson (1994), apontam que do total infiltrado de $3 / 4$ do volume da entrada na trincheira de infiltração. Estudos apontam positivamente o auxílio das trincheiras em relação a drenagem pluvial, com capacidade de infiltrar $63,57 \%$, tendo uma compensatória no manejo das águas pluviais urbanas. 


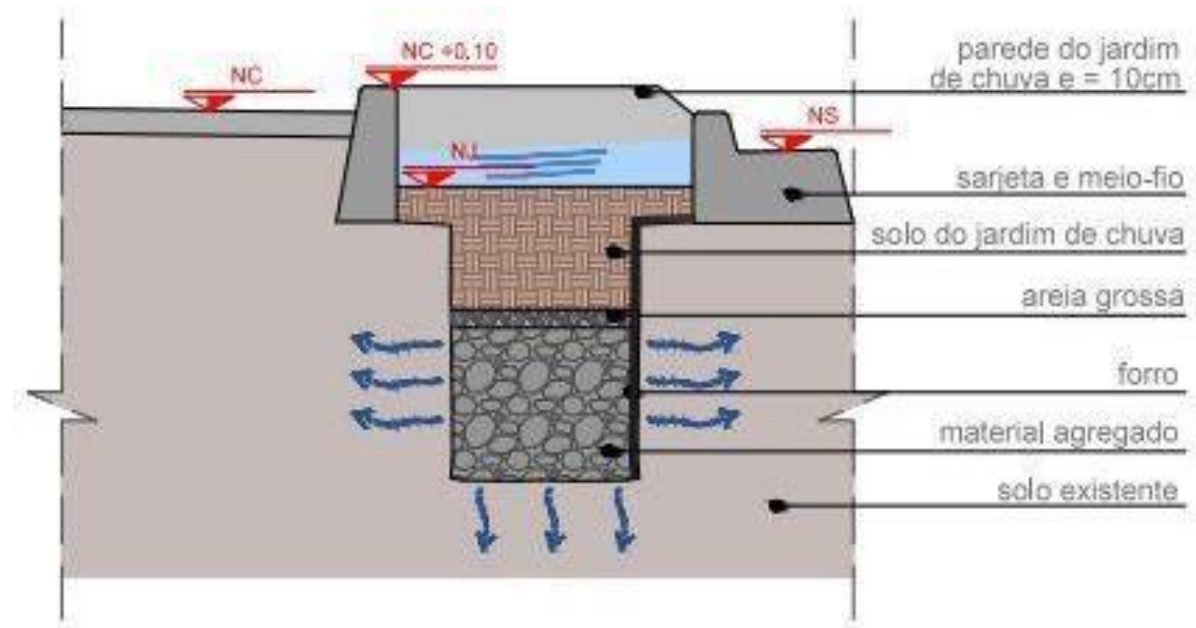

\section{CORTE AA}

\subsection{JARDINSDECHUVA}

É um jardim de arbustos nativos, perenes e flores plantadas em uma pequena depressão do terreno, que geralmente é formada em uma encosta natural. Ele é projetado para reter temporariamente e absorver o escoamento da água da chuva que flui de telhados, pátios, gramados, calçadas e ruas.

Para que o sistema funcione adequadamente e não polua o aquífero, deve ter seu fundo impermeabilizado, sua capacidade vária de infiltração é de 7 a $200 \mathrm{~mm} / \mathrm{h}$.

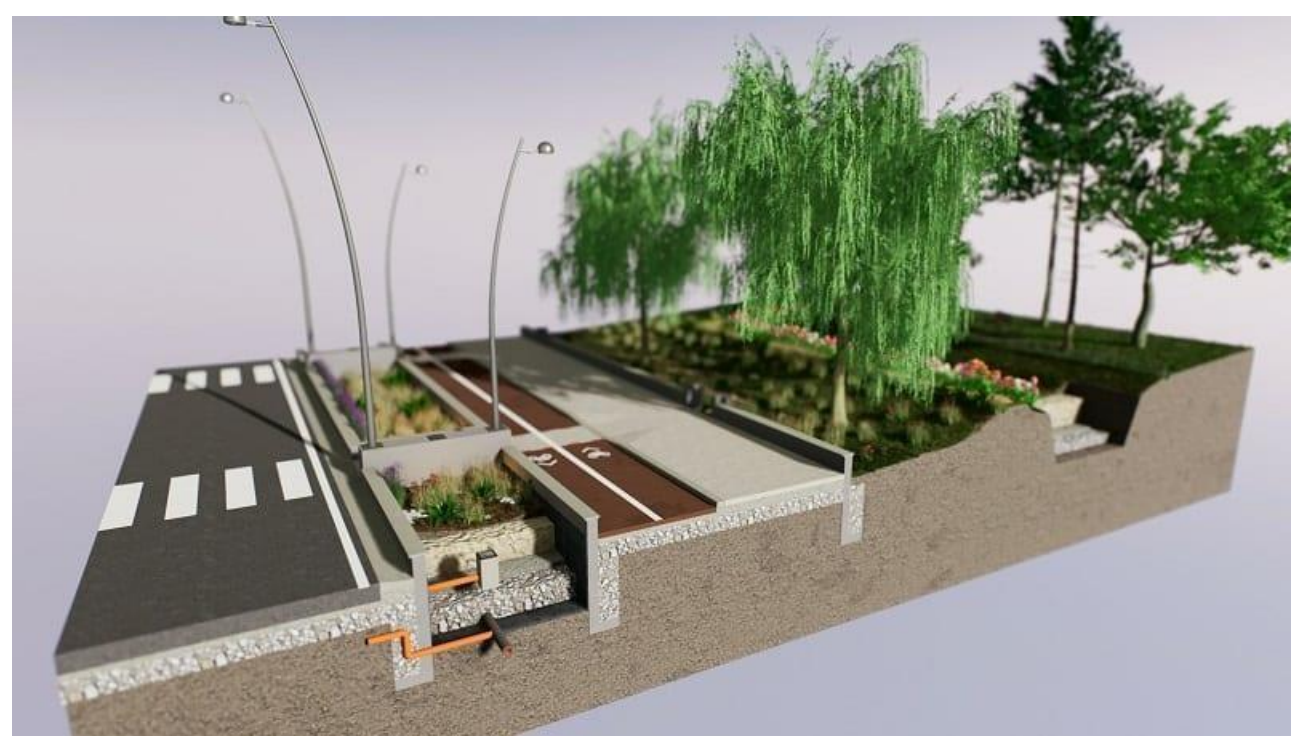

\subsection{COMBINADO DE MEIO-FIO E DRENAGEM}

O sistema combinado de meio-fio e drenagem foi feito para ser parte integrante do gerenciamento da água de chuva, além de ser uma solução nova e sustentável. A fabricação desse sistema é feita com concreto polímero, a peça é única facilitando sua utilização em qualquer ponto das ruas.

O produto tem sobrenome de eficiência, pois combina com os paisagismos e reduz drasticamente a entrada de sujeiras, pedras ou lixo no sistema pluvial. Segundo o site New Roads de 2018, "em reconhecimento a sua tecnologia e o design único, ACO Kerbdrain já recebeu inúmeros prêmios internacionais. Possui certificado de homologação CE para Classes de Carga até D 400 e está de acordo com a norma EN1433: 2002."

Então com a colocação do meio-fio, agilizando o assentamento, em conjunto com a economia no orçamento e o grande auxílio na drenagem convencional. 

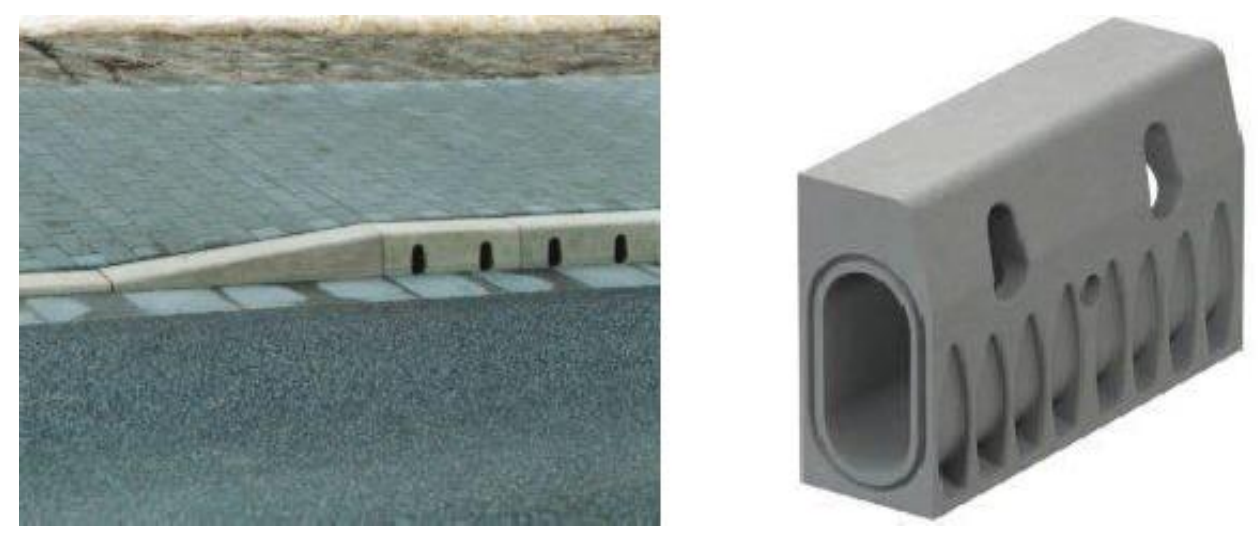

\subsection{RESULTADOS}

Para o dimensionamento da galeria a metodologia utilizada foi o cálculo racional. Esta metodologia foi à solução mais adequado para o dimensionamento da rede de drenagem tradicional que comporta até $2 \mathrm{~km}$ de bacia, utilizando o mesmo traçado da rede, e delimitação das áreas contribuintes, a partir da planta do local cedida pela Prefeitura Municipal.

O cálculo da vazão de projeto foi feito através do método racional, e a implantação de acordo com as normas NBR e demandas Municipais. Já os parâmetros da bacia, foram definidos pelo traçado das ruas e divido em 4 bacias para não sobrecarregar a rede, contando com 3 lançamentos.

O tempo de retorno, e o tempo de concentração de entrada vindo das sarjetas foram considerados de acordo com as normas da cidade e do método utilizado para cálculo. Pode ser compreendido que com a junção da drenagem pluvial e o meio ambiente se criaria o sistema ideal, que além de aliviar a drenagem convencional quase por completo, estaria evitando interferência no meio ambiente e em vários outros problemas causos por enchentes, por exemplo.

Podemos compreender que através da junção da drenagem pluvial e meio ambiente seria o sistema ideal, aliviando a drenagem convencional quase que por completo usando alguns métodos como os citados acima. Além de aliviar a interferências das obras nos rios, lagos e córregos.

É de conhecimento que segundo a normal Lei Complementar ํㅡ 806, de 4 de abril de 2.011 de Araraquara, diz sobre o parcelamento do Solo Urbano que são destinados $20 \%$ para circulação, $10 \%$ para área institucional, $10 \%$ para área de lazer e $5 \%$ de espaço livre de uso. Portanto para meios comparativos, foi adotado $60 \%$ de áreas para lotes e desta mesma porcentagem foi tirado mais $5 \%$ para o cálculo da trincheira.

Para aliviar a rede de drenagem e verificar o quanto seria possível ter a menor interferência na implantação das galerias, a possibilidade da vazão é a primeira etapa é de $7,613 \mathrm{~m}^{3} / \mathrm{s}$, sabendo que a área total das bacias é de $459.232,77 \mathrm{~m}^{2}$, tirando $60 \%$ dessa área para calcular para a área de uma trincheira, a área útil é de 275.539,66 $\mathrm{m}^{2}$.

Com a área definida, segunda as pesquisas devem ser usadas até 5\% para calcular a área da trincheira, totalizando $13.776,98 \mathrm{~m}^{2}$ para as trincheiras. Sendo assim, está área será dividida em 4 para cada bacia, então para primeira etapa sua área seria de $3.444,25 \mathrm{~m}^{2}$, aliviando a rede em até $63 \%$, diminuindo a vazão desta rede e chegando à $4,796 \mathrm{~m}^{3} / \mathrm{s}$.

Portanto é possível compreender que utilizando somente uma das alternativas sustentáveis, a vazão que chega na rede convencional será reduzida praticamente pela metade, com menor interferências no meio ambiente e também uma rede de galeria pluvial menor.

\section{CONCLUSÃO}

É imprescindível a necessidade dos sistemas construtivos caminhe em conjunto com o desenvolvimento sustentável, entendendo que o custo será menor, a mobilização e interferências também serão menores e tudo isso sem perder qualidade no sistema construtivo da galeria pluvial.

O objetivo principal dos dispositivos sustentáveis é o de amenizar o escoamento para jusante, reduzindo a vazão e por consequência diminuindo assim os riscos provocados. Sendo possível com todos os estudos disponibilizados sobre o assunto, além da prática desenvolvida nos países citados, fazendo ser possível conhecer as vantagens e desvantagens para relacionar a viabilidade ou não de seu uso. 
Por consequência o saneamento é parte importante em tudo sistema construtivo de infraestrutura de uma cidade, é esperado que com essas tomadas de decisões sustentáveis, é esperado a diminuição de inundações da região, diminuindo também doenças transmitidas pela água.

Portanto, é imprescindível que nos próximos projetos de galerias sejam implantadas soluções que ajudem na diminuição de sujeira na tubulação, mas auxílio no escoamento, não sobrecarregando o sistema e conferir demais possíveis inviabilidades para a implantação da técnica, assim como estudos econômicos mais aprofundados, uma base de infraestrutura prévia no local, verificação sobra a estrutura planejada suportaria a demanda necessária e adquirir novas tecnologias de construção. 


\section{REFERÊNCIASBIBLIOGRÁFICAS}

CAPA DA ABNT. IN: NORMAS ABNT: HTTPS://WWW.NORMASABNT.ORG/CAPA-DE-TRABALHOABNT/.ACESSO EM:21 ABRIL 2021

CICLO ÁGUA. IN: MUNDO EDUCAÇÃO:

HTTPS://MUNDOEDUCACAO.UOL.COM.BR/BIOLOGIA/CICLO-AGUA.HTM.ACESSOEM: 14JUNHO 2021

RGS ENGENHARIA. IN: DRENGEM

URBANA:HTTPS://WWW.RGSENGENHARIA.COM.BR/BLOG/DRENAGEM-URBANA-ENTENDA-OQUE-E-E-SUA-IMPORTANCIA

. ACESSO EM: 14 JUNHO 2021

LEI 11445. IN: PLANALTO HTTP://WWW.PLANALTO.GOV.BR/CCIVIL_03/_ATO2007-

2010/2007/LEI/L11445.HTM. ACESSO EM: 14 JUNHO 2021

ÁGUA E SANEAMENTO. IN XVIII ENANPUR:

HTTP://ANPUR.ORG.BR/XVIIIENANPUR/ANAISADMIN/CAPAPDF.PHP?REQID=1687. ACESSO

EM: 14 JUNHO 2021

TUCCI, C.E.M.; COLLISCHONN, W.. DRENAGEM URBANA E CONTROLE DE EROSÃO. VI SIMPÓSIO NACIONAL DE CONTROLE DA EROSÃO. ANAIS. PRESIDENTE PRUDENTE, SÃO

PAULO, 1998, 6. JG., P. 128-130

MANUAL DE DRENAGEM URBANA. IN TOLEDO:

HTTPS://WWW.TOLEDO.PR.GOV.BR/SITES/DEFAULT/FILES/MANUAL_DE_DRENAGEM_URBAN A_-_VOLUME_I.PDF. ACESSO EM: 20 JUNHO 2021

LUISMASCARÓ, RUAN.LOTEAMENTOS URBANOS.PORTO ALEGRE-2005.

TUCCI,C.E.M.1993.HIDROLOGIA:CIENCIAEAPLICÇÃO.EDITORADAUFRGS,ABRH.

CHUVAS SP. IN:LED ESALQ :

HTTP://WWW.LEB.ESALQ.USP.BR/LEB/DISCIPLINAS/FERNANDO/LEB1440/AULA\%203/DAEE_E Q_CHUVAS_SP.pdf. 24 NOVEMBRO 2021

OBRAS HIDRÁULICAS. IN:DAAE: GUIA PRÁTICO PARA PEQUENAS OBRAS HIDRÁULICAS, DAEE - 2005. 24 NOVEMBRO 2021

TUCCI, C. E. M.2004.HIDROLOGIA: CIÊNCIA E APLICAÇÃO. 3ª ED., UFRGS EDITORA.

ÁGUAS PLUVIAIS. IN: DEGRAUS HTTPS://WWW.DEGRAUS.COM.BR/DRENAGEM-DE-AGUASPLUVIAIS-ENTENDA-COMO-FUNCIONA/.ACESSO EM: 25 NOVEMBRO 2021

TRINCHEIRAS. IN: SCIELO:

HTTPS://WWW.SCIELO.BR/J/AC/A/GGHRQ58K36HBFDYJ8ZQ5ZMV/?LANG=PT. ACESSO EM: 25 NOVEMBRO 2021 